\title{
Management of zygomatic-maxillary fracture (The principles of diagnosis and surgical treatment with a case illustration)
}

\author{
David B. Kamadjaja and Coen Pramono D \\ Department of Oral Maxillofacial Surgery \\ Faculty of Dentistry Airlangga University \\ Surabaya - Indonesia
}

\begin{abstract}
Mechanical trauma to the face may cause complex fracture of the zygoma and the maxilla. The characteristic clinical signs of zygomatic bone fracture include flattening of the cheek, infraorbital nerve paraesthesia, diplopia, and trismus, whereas maxillary fracture may typically cause flattening of the midface and malocclusion. The diagnosis of zygomatic and maxillary fracture should be established with thorough clinical examination and careful radiologic evaluation so that a three-dimensional view of the fractured bones can be obtained. This is essential in order to plan a proper surgical treatment to reconstruct the face in terms of functions and aesthetic. A standard surgical protocol should also be followed in performing the surgical reconstruction of the zygoma and the maxilla. A case of delayed bilateral fracture of zygoma and maxilla is presented here to give illustration on how the principle of diagnosis and surgical treatment of complex zygomatico-maxillary fracture are applied.
\end{abstract}

Key words: zygomatico-maxillary fracture, occlusion rehabilitation, malar prominence correction, bone plating

Correspondence: David B. Kamadjaja, c/o: Departmen Bedah Mulut dan Maksilofasial, Fakultas Kedokteran Gigi Universitas Airlangga. Jln. Mayjend. Prof Dr. Moestopo no. 47 Surabaya 60132, Indonesia. E-mail: davidbk@ sby.dnet.net.id

\section{INTRODUCTION}

Trauma to the midface may cause fractures affecting the maxilla, the zygoma, and the nasoorbital ethmoid complex. Depending on the mechanism of injury, it is not uncommon that fracture of the midface involve both the zygoma and the maxillary bone. ${ }^{1,2}$

The zygomatic bone or zygoma is a strong buttress of the lateral portion of the middle third of the facial skeleton lying between the zygomatic processes to the frontal bone and the maxilla. Due to its prominent position, it is frequently fractured, alone or along with other bones of the midface. Direct blows usually first strike on the most prominent part which is the malar eminence. This causes disruption at the relatively weaker part which are the zygomatic arch, the frontal process, and the zygomaticomaxillary suture. ${ }^{3}$ The clinical signs and symptoms are related to displacement or rotation of the fragments which include enophthalmos, hypothalmos, proptosis, diplopia, trismus, mallar flattening, and hypoesthesia. ${ }^{1-5}$

A number of classifications for zygomatic fractures have been developed based on the anatomy and displacement of the fracture. The most widely used classification of zygomatic fracture are those proposed by Dingman and Rowe and Killey's. ${ }^{5}$ These classifications indicate that comminuted fractures and those demonstrating lateral displacement of the zygomatic complex, are unstable after closed reduction (Figure 1).

Maxillary fracture is defined as the separation of parts or the entire tooth-bearing part of the maxilla from the residual midface or the neurocranium. Among facial
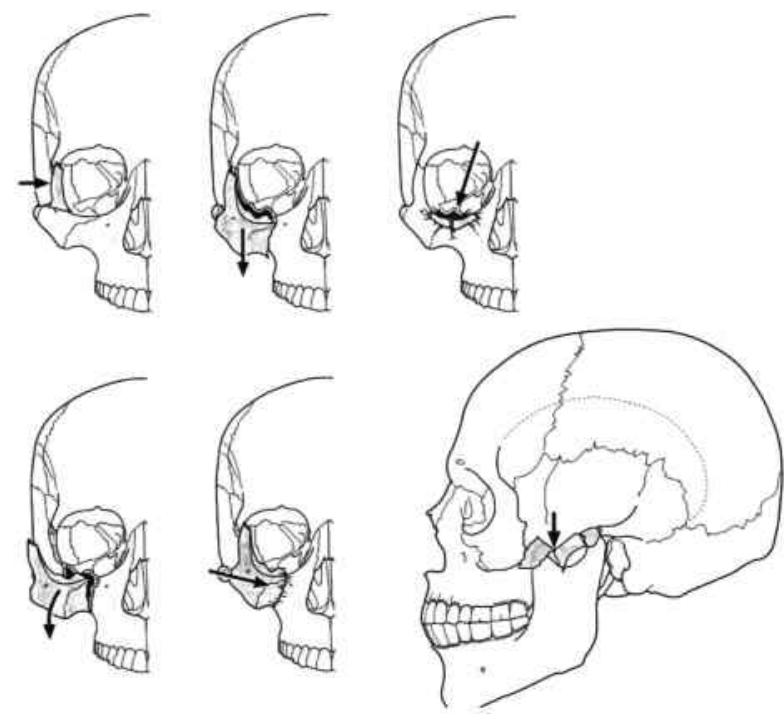

Figure 1. The fracture scheme of Rowe and Killey indicates the fractures that are more stable following closed reduction. Those that are alterally displaced and/or comminuted are less stable if treated by closed reduction. ${ }^{5}$

bone fractures, maxillary fractures are less fequent than nasal bone fractures, mandibular fractures, and zygoma fractures. Current studies report an incidence of $14 \%$ of all facial fractures. ${ }^{6}$

The clinical symptoms of maxillary fracture may vary depending on the level at which the maxillary bone 
fractures. The common symptoms include: swelling of the facial soft tissues, retrusion of the midface, bleeding from the nose, and in many cases, unilateral or bilateral orbital hematomas. Careful palpation may reveal bony steps and tenderness on the orbital rings and over the crista zygomaticoalveolaris, diplopia, sensory disturbance of the infraorbital nerves, and occlusal problems, mostly in the form of anterior open bite and premature contact in the molar region. ${ }^{1,3}$

The diagnosis of fracture of zygoma and maxilla can usually be made with thorough clinical examination and adequate radiological evaluation. Plain radiograph commonly used in midfacial fracture is occipito-mental or Water's view which can clearly demonstrate the bone discontinuity in the zygomaticomaxillary buttress and the inferior orbital rim. The submentovertex view more clearly detects fractures of the zygomatic arch. CT scan and its three-dimensional applications is indicated for visualization of the orbit if the orbital portion of the zygomatic fracture is suspected. Once the diagnosis is established a surgical treatment plan can be made. The current principle of treatment of maxillofacial fracture is open reduction and rigid fixation and in a complex fracture of the zygoma and the midface a certain surgical plan should be followed in order to have good result. ${ }^{5}$

A case of complex zygomatic-maxillary fracture is presented below to give illustration on how the principles of diagnosis and surgical treatment discussed above are applied.

\section{CASE}

A forty-year old male patient came to Department of Oral and Maxillofacial Surgery, Faculty of Dentistry, Airlangga University, Surabaya with chief complaint of inability in chewing after having accident in a liner where he was working 8 days previously. He felt from height and sustained injury on his face. Shortly after the accident there was large swelling over his face on both sides and he noticed bloody discharge from his nose. He also complained that his upper jaw was moving whenever he tried to chew.

On clinical presentation, his right malar prominence was obviously depressed, and right periorbital ecchymosis and subconjunctival haemorrhage were still seen. Few stitches were noted over a $3 \mathrm{~cm}$-long laceration in right supraorbital region (Figure 2). Eye ball movement were normal in all directions on both sides. Bony step was felt on the right frontozygomatic suture and paraesthesia found over the infraorbital region bilaterally. Intra orally, floating maxilla was clearly detected, malocclusion was noted showing anterior and posterior open bite on both sides and the absence of normal interdigitation of the upper and

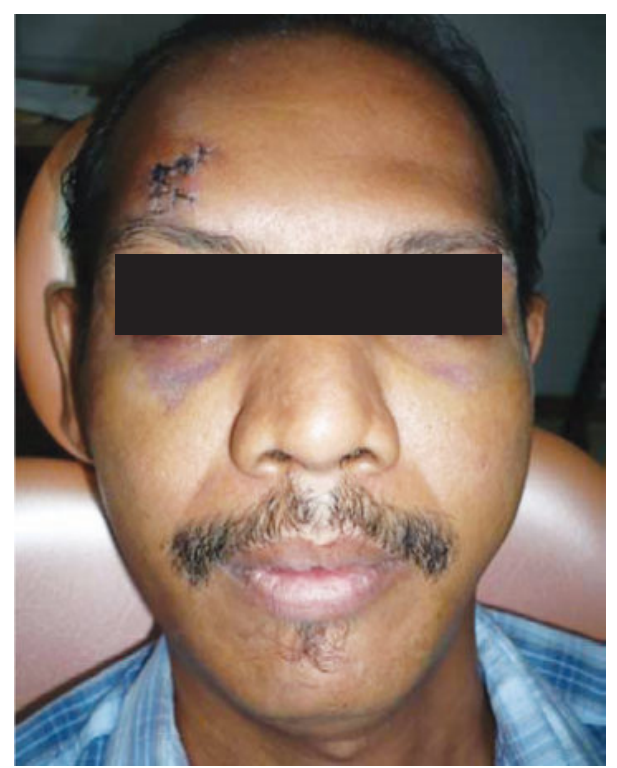

Figure 2. The molar prominence on the right side was obviously depressed giving the appearance of flat cheek.
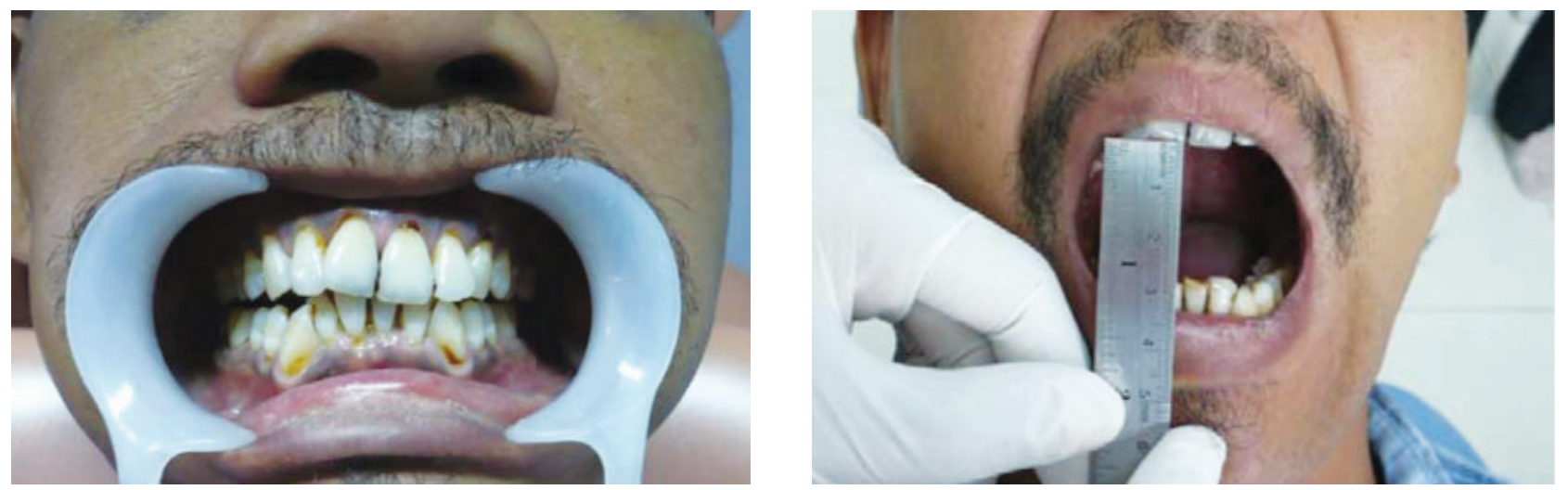

Figure 3. Anterior and posterior open bite were noted on both sides with the absence of normal interdigitation between upper and lower teeth (left). Maximum mouth opening showing acceptable interincisal distance of $27 \mathrm{~mm}$ (right). 
lower dentition (Figure 3). However, he showed acceptable mouth opening with maximum interincisal distance of $27 \mathrm{~mm}$ (Figure 2), but slight restriction and discomfort were reported by the patient during maximum opening.

Plain imagings available at his first presentation were postero-anterior and lateral skull x-ray, and occipitomental view which showed clearly displaced fracture on the right frontozygomatic suture and on the pterygomaxillary buttress bilaterally, minimally displaced fracture on the left frontozygomatic suture, and seemingly fracture right inferior orbital rim (Figure 4). Orthopantomogram was
The surgery was done under general anesthesia using halothane via nasal intubation. It was initiated by making vestibular incision from the region of upper first molar to the same region on the opposite side to expose the maxilla up to malar prominence, pterygoid, and nasomaxillary regions. Displaced fractures were found to run horizontally at a high Le Fort I level on both sides of the maxilla. The right zygoma was found to be severely displaced medially and posteriorly, whereas the left zygoma was relatively stable. The infraorbital neurovascular bundles on both sides were involved in the fracture site but seemed intact. (Figure 5).
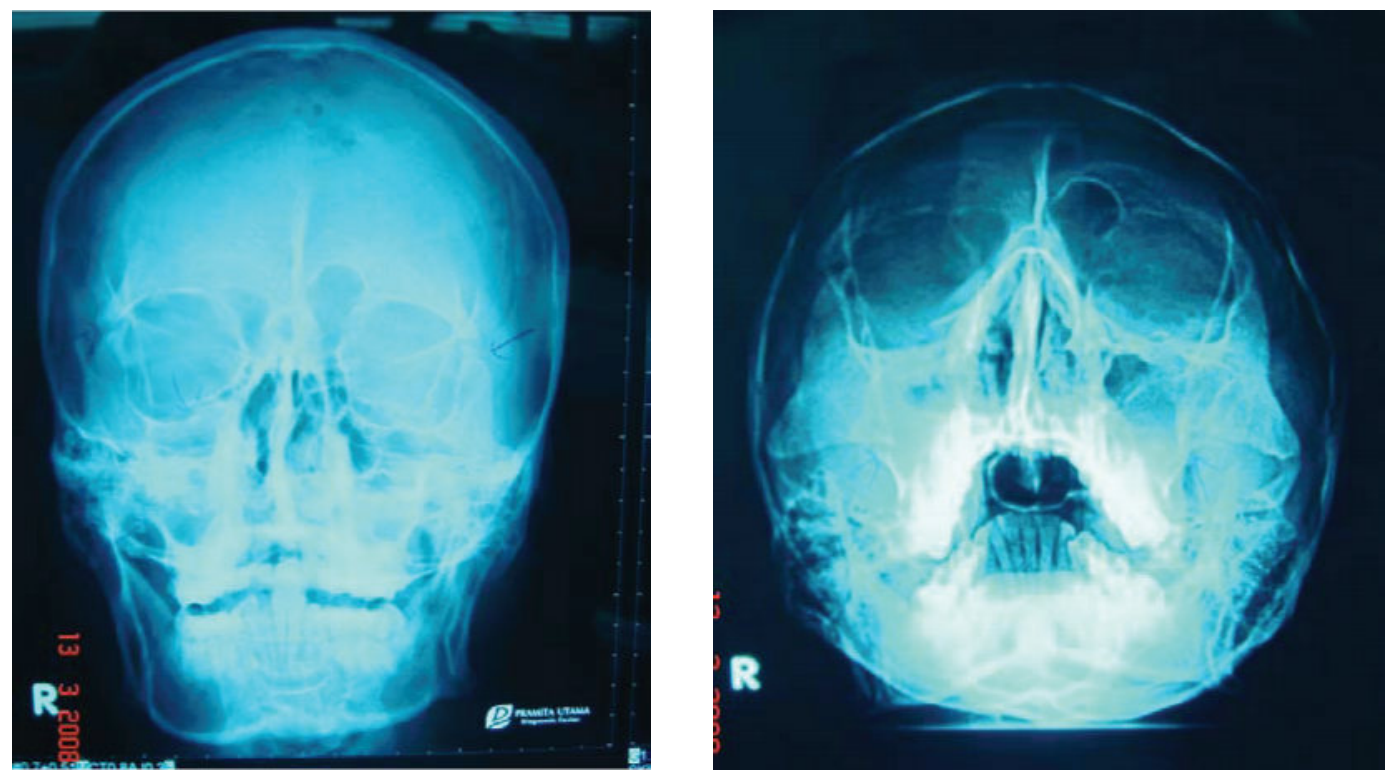

Figure 4. PA Skull x-ray showing severely displaced fracture at the right frontozygomatic suture and minimally displaced fracture at the left frontozygomatic suture (left), (B) Water's projection clearly showing bone displacement in zygomatico-maxillary buttress on both sides and at the right frontozygomatic suture, and seemingly fracture inferior orbital rim on the right side.

subsequently made which revealed that the mandible was intact and no abnormality detected.

The diagnosis made was displaced fracture of the right zygomatic complex and bilateral Le Fort I fracture of the maxilla. The planned surgery to reconstruct the face was open reduction and internal fixation using miniplates and screws to fix the right zygoma followed by fixation of the maxilla on both sides, and exploration of the right coronoid process of the mandible to exclude any restriction to the movement of coronoid process which may be secondary to zygomatic arch fracture.

\section{CASE MANAGEMENT}

Some preparations was made two days prior to the surgery which were dental scaling to the upper and lower teeth and placement of intermaxillary fixation using arch bars and elastic rings. Acceptable occlusion was readily achieved upon completion of the intermaxillary fixation.
The right eye brow incision was made which revealed displaced fracture on the right fronto-zygomatic suture. Right infra orbital stepped incision was subsequently made to expose the inferior orbital rim. It was found that the right inferior orbital rim was intact, no fracture line was detected.

The right zygoma was subsequently reduced using two periosteal elevators applied underneath the malar bone and the frontal process of the zygoma to move the fragment laterally and anteriorly. With this maneuver the zygoma was successfully repositioned without much effort as no callus formation had been formed. The fracture site at the right fronto-zygomatic region was fixed with one titanium miniplate and four screws, whereas the right Le Fort I fracture was fixed with two miniplates placed at the right zygomatico-maxillary buttress and nasomaxillary buttress respectively (Figure 6).

The Le Fort I fracture on the left side was subsequently reduced with the same elevator. The reduction was successfully accomplished more easily compared to the 
right side. The fixation was then made using two stemmed titanium miniplates placed along the left zygomaticomaxillary and nasomaxillary buttresses (Figure 7). The bony fracture at the left frontozygomatic area was not reduced as it was only minimally displaced and the left zygomatic bone as a whole was relatively stable.

The intermaxillary fixation was released to check the stability of the occlusion and the range of motion of the
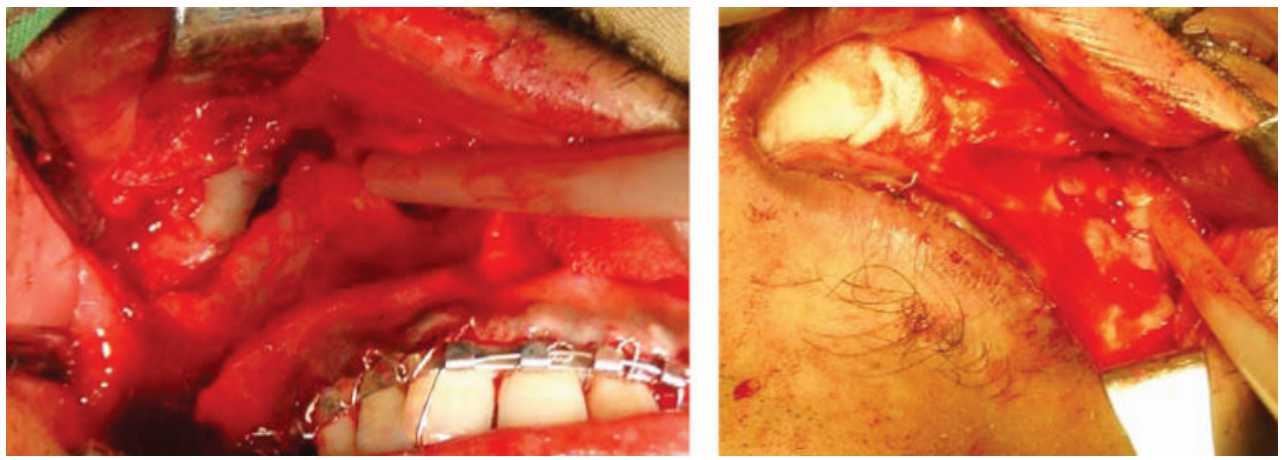

Figure 5. Displaced fracture of the right maxilla were found to run horizontally at a high Le Fort I level which cause the body of the right zygoma to be severely displaced medially and posteriorly, infraorbital neurovascular bundle involved in the fracture line and compressed by the displaced bone fragments (left); High Le Fort I fracture line on the left maxilla with minimally displaced left zygoma, the infraorbital neurovascular bundle also involved in the fracture line.
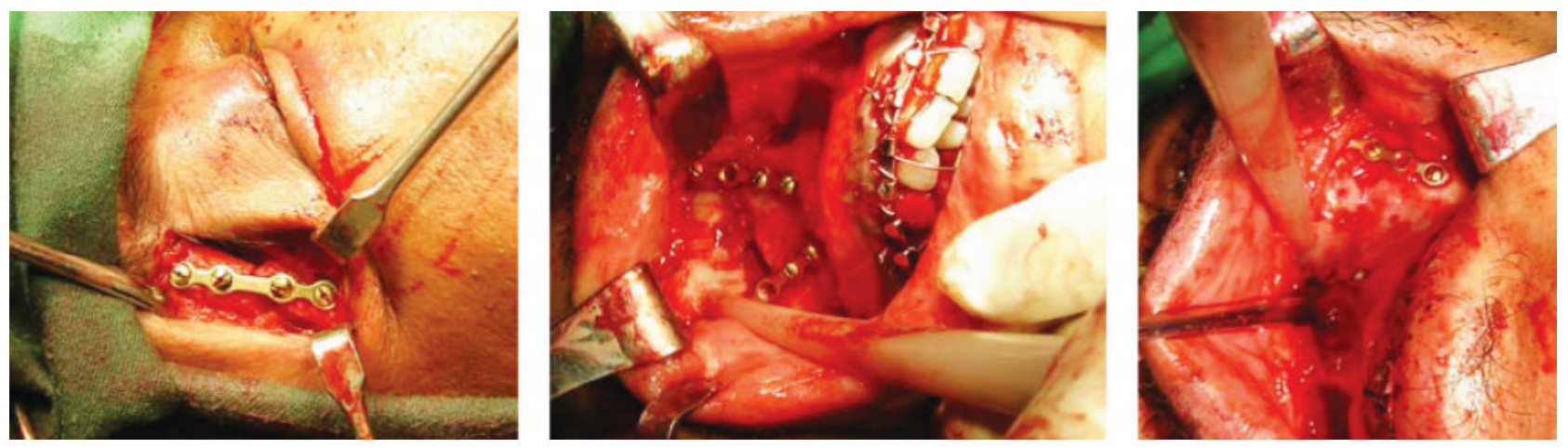

Figure 6. Following complete reduction of the fracture bones, the right zygoma is fixed first to the stable frontal bone, followed by fixation of the maxilla on both sides to the stable zygoma. Fracture at right frontozygomatic bone fixed with one stem of titanium miniplate and four screws. (left); Le Fort I fracture of the right maxilla fixed with two stem of miniplates placed at the right zygomatic buttress laterally and nasomaxillary buttress medially (center); two stem of miniplates placed in the same fashion on the left maxilla (right).
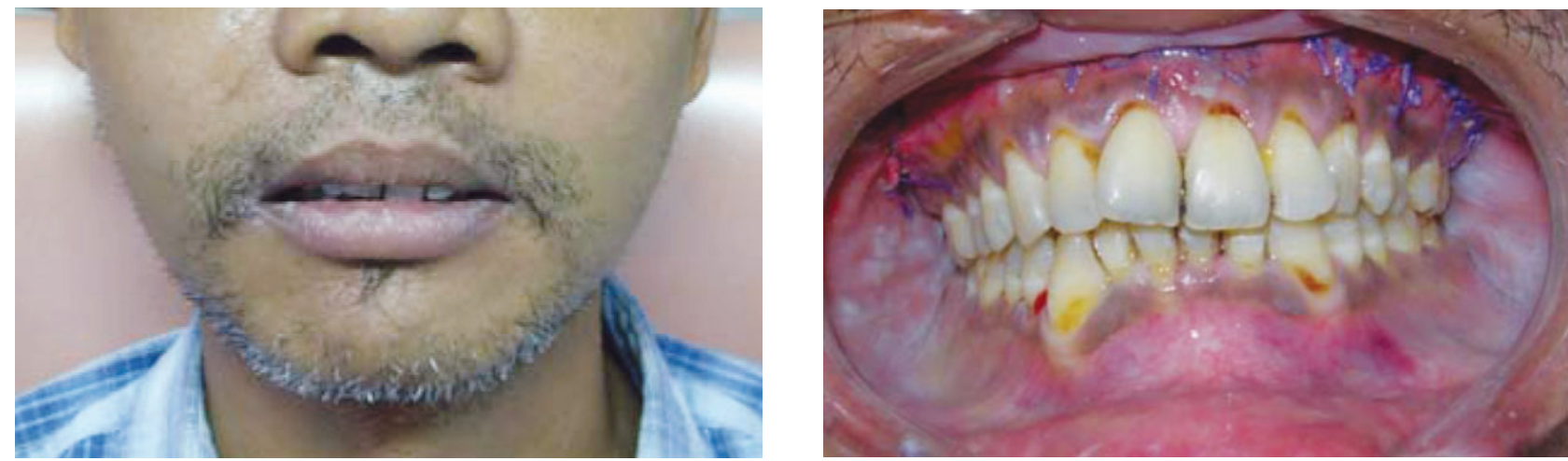

Figure 7. Review 7 days after the surgery showing remnant of facial swelling on the right cheek obscuring the prominence of the right malar bone (left); good and stable occlusion (right). 
mandible. A digital exploration was then made to the right temporal region which revealed that the coronoid process movement was not restricted indicating that the zygomatic arch was not displaced medially.

The operation wound on the skin of the right eye brow was closed with 5/0 Prolene suture. The infraorbital region was closed in two layers in which the periosteum and the orbicularis oculi muscle were stitched back with $4 / 0$ Vycril suture and the overlying skin with 5/0 Prolene, whereas the intraoral wound was closed using 4/0 Vycril.

Post operatively large facial swelling was noted especially on the right side. He stayed at the hospital for three days during which time he was put on a soft diet. The oral hygiene was maintained with chlorhexidine mouth wash. Intravenous ceftriaxone injection and metronidazole drip was given with the dosage of $2 \mathrm{~g} /$ day and $1.5 \mathrm{~g} / \mathrm{day}$ respectively for four post-operative days. Upon discharge, clindamycin $300 \mathrm{mg} 3$ times a day was prescribed and the patient was advised to have non-chewing diet for one month.

Post operative review done 7 days post operatively showed that the facial swelling was still present but the malar prominence on the right side seemed acceptable (Figure 6). The paraesthesia over the skin of the infraorbital region was still noted but the sensation has somewhat improved. The mouth opening remained the same as that measured prior to the surgery and the maxilla as well as the occlusion were stable. Post operative postero-anterior skull $\mathrm{X}$-ray was made to show the orientation of the miniplates along the midfacial buttresses (Figure 8).

At one month postoperative review, the patient did not complain of any pain nor difficulty in eating, and he was very satisfied with his appearance. The sensation over his infraorbital skin on both sides was coming back to a certain degree. Clinically, although remnant of swelling

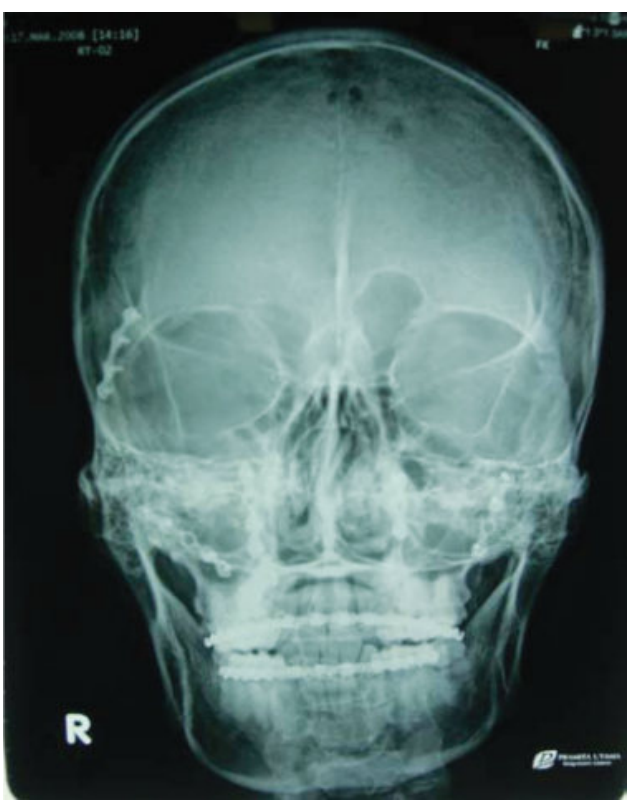

Figure 8. Post operative PA skull x-ray showing orientation of the miniplates along the midfacial buttresses.

over the infraorbital region was still present the face appeared simetrical with nice malar prominence on both sides. Intraorally, the the maxilla was stable and so was the occlusion. The patient's mouth opening showed normal maximum interincisal distance of $35 \mathrm{~mm}$ (Figure 9).

\section{DISCUSSION}

Fracture of the zygoma complex has a characteristic clinical sign of flattening of the normal prominence in the malar area, especially in zygomatic complex injuries. It is
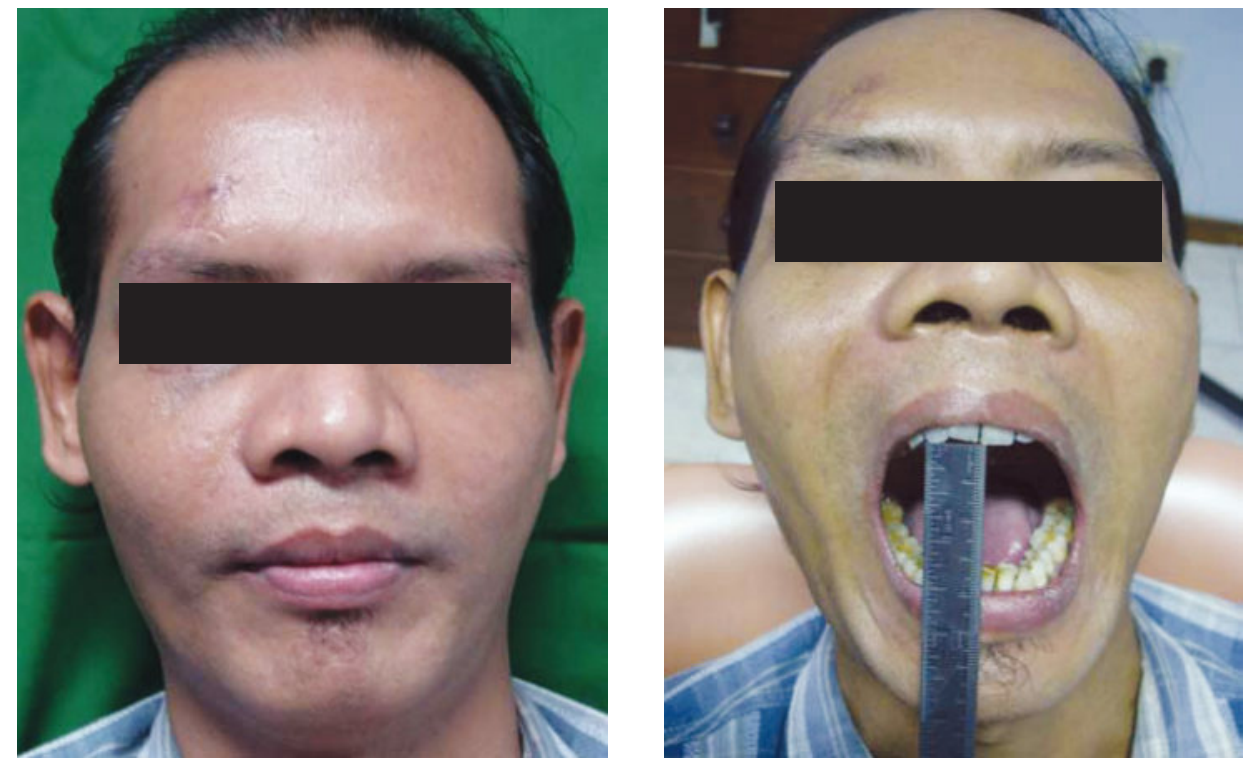

Figure 9. One month postoperative review. The face looks simetrical with nice malar prominence on the right side (left); the patient's mouth opening showing normal maximum interincisal distance of $35 \mathrm{~mm}$ (right). 
reported in 70 to 86 percent of cases. ${ }^{7}$ In the case reported herein, flattening of the right malar prominence was obvious, although the patient did not really notice it when presented to our clinic. It is most probably due to the fact that flattening may be difficult to discern soon after injury if the facial edema is still present. ${ }^{8}$

The other characteristic signs of zygoma fracture which mandate surgery are diplopia, trismus, and paraesthesia of the infraorbital skin. Diplopia is usually caused by fracture of the orbital floor which result in entrapment of the periorbital fat and the subsequent tathering of the extraocular muscles. Trismus which occured after zygoma complex fracture is usually caused by medially displaced fracture of the zygomatic arch which impinge on coronoid process of the mandible resulting in restriction of the mandibular movement. The infraorbital nerve paraesthesia is also commonly found in zygomatic complex fracture as the nerve is involved in the fracture site in the form of tear or compression by the surrounding tissue. ${ }^{8}$

Out of the above signs only infraorbital paraesthesia which was clearly present in the current case. During surgery it was found that the infraorbital nerve on both sides were involved in the fracture sites but macroscopically they seemed intact. The findings indicate that neuropraxia may have happened to the nerves due to compression by the fracture bone around them. The pre operative mouth opening of $27 \mathrm{~mm}$ might indicate that there was some restriction to the mandible movement. Since zygomatic fracture was not suspected in this case, this phenomenon may be secondary to swelling of the soft tissue deep to the fractured zygomatic complex on the right side which has caused some compression on the right coronoid process of the mandible. Clinical review one month postoperatively which showed a normal mouth opening of $35 \mathrm{~mm}$ seems to support our hypothesis.

The diagnosis of bilateral Le Fort I fracture of the maxilla in the case presented here was established based on clinical and radiologic findings. As he came to us eight days after the accident some of the clinical signs and symptoms of maxilla fracture might have disappeared. The only clinical signs of Le Fort I fracture exhibited by the patient were anterior and posterior open bite and floating of the maxilla. The radiologic findings that support Le Fort I fracture is occipito-mental view x-ray which showed bone discontinuity at the region of zygomaticmaxillary buttress bilaterally

The midface is a complex three-dimensional structures, therefore recreating the facial functions and aesthetics would ideally requires a precise three-dimensional view of all the traumatized structures. In vew of this, CT scan and its three-dimensional application is essential in establishing the final diagnosis before surgical treatment is planned. ${ }^{9}$ However, a number of midfacial and zygomatic fracture cases in our department are not provided with CT scan as this type of imaging is still considered relatively expensive in this part of the country and this is the case with this patient. Therefore the surgical reconstruction was planned based mainly on the clinical judgment and the plain imagings which are postero-anterior skull, occipitomental view, and orthopantomogram.

In complex fracture of the zygoma and Le Fort I fracture of the maxilla, the surgical plan follows a certain principle that the treatment should begin with reconstruction of the load-bearing structures of the facial skeleton starting peripherally and moving centrally and that the building up of the face begins by establishing the anteroposterior dimension by reconstructing the outer facial frame, starting from the stable posterior regions and continuing toward the midline. ${ }^{5}$ It is suggested that open reduction and fixation of zygomatic arch and frontozygomatic fracture using miniplates results in the establishment of an outer facial frame with the correct anteroposterior projection and transverse facial width. The inner facial frame composed of nasoethmoid, inferior orbital rims, and upper maxilla is now reconstructed within this outer facial frame by building from the nasofrontal region above and the inferior orbital rim below. The lower facial frame is reconstructed last by establishing accurate intermaxillary fixation in combination with reduction and fixation of the four medial and lateral anterior maxillary buttresses using miniplate and screws. ${ }^{12}$

The zygomatic bone in the reported case sustained fracture in the frontozygomatic and zygomaticomaxillary buttresses. Although neither submentovertex view nor CT scan was made prior to the surgery we assumed that zygomatic arch was intact, judged by the clinical presentation of the lateral part of the face and the absensce of trismus. Therefore, fixing the frontozygomatic buttress alone was sufficient to achieve a stable outer facial frame.

After fixation of the right frontozygomatic buttress with miniplates has been done the bilateral Le Fort I fracture was subsequently reconstructed based on the stable zygoma. The reconstruction of the maxilla should be initiated only when a proper occlusion has been established and this can be achieved only when the mandible is stable. The sequencing of treatment of complex facial trauma should follow the rule that mandible should be stabilized first before maxillary stabilization as the maxilla can be built on an exact occlusion in intermaxillary fixation as key and fixpoint. ${ }^{10}$ As our patient's mandible was intact fixed occlusion can be achieved by placing intermaxillary fixation using arch bar and elastic rings two days prior to the surgery. The intermaxillary fixation was kept in place until the day of the surgery. This procedure is very useful because it could reduce the length of the surgery in the operating theatre.

The current method of treatment in maxillofacial, including midface, fracture is open reduction and internal fixation with miniplates and screws which offers stable reduction of the fracture fragments. This would consequently allow for early mobilization of the jaw thus early and optimal recovery of function and esthetic. ${ }^{11}$ In order to fix the maxilla to its lateral and superior structures the miniplates were placed laterally in the pterygomaxillary 
buttress and medially in the nasomaxillary buttress since these buttresses are the pillars consisting of thicker bone that transmits the chewing forces to the supporting regions of the skull. ${ }^{12,13}$

The midface fractures has tendency to quick and spontaneous healing especially in non-displaced fractures where the maxilla is immobile or only slightly mobile. However, it may be disadvantageous in such clinical situation as when the trauma team needs several days to stabilize the patient and the maxillofacial surgeon cannot intervene early enough, the fractures may have begun to consolidate in displaced positions. Fourteen days is the upper limit of primary facial reconstruction in midfacial fractures. ${ }^{6}$ It is suggested that reduction and fixation up to 3 weeks after trauma produces satisfactory results. After this time, bone healing and resorption begin to take place, and this period has been referred to as a gray time zone. ${ }^{13}$ This applies to the case presented here. As the bony fracture in the zygoma and the maxilla were still eight days old then it is reasonable that bone consolidation was not found during the surgery and the displaced zygomatic complex could be reduced without much difficulty.

\section{REFERENCES}

1. Peterson L. Contemporary oral and maxillofacial surgery. $2^{\text {nd }}$ ed. St. Louis: Mosby; 1993. p. 597.
2. Gruss J, van Wyck L, Phillips JH, Antonyshyn O. The importance of the zygomatic arch in complex midfacial fracture repair and correction of posttraumatic orbitozygomatic deformities. Plast Reconstr Surg 1990; 85:878-89.

3. Kaastad E, Freng A. Zygomatic-maxillary fractures. J Craniomaxillofac Surg 1989; 17:210.

4. Carr MR, Mathog RH. Early and delayed repair of orbitozygomatic complex fractures. J Oral Maxillofac Surg 1997; 55:253-8.

5. Booth PW, Schendel SA, Hausamen JE. Maxillofacial surgery. $2^{\text {nd }}$ ed. St. Louis, Missouri: Churchill Livingstone; 2007. p. 104-19, 120-54.

6. Gassner R, Tuli T, Hachl O. Craniomaxillofacial trauma: a 10-year review of 9,543 cases with 21,067 injuries. J Craniomaxillofac Surg 2003; 31(1):51-61.

7. Ellis E., El-Attar A, Moos KF. An analysis of 2,067 cases of zygomatico-orbital fracture. J oral Maxillofac Surg 1985; 43:428.

8. Fonseca RJ, Walker VW. Bett NJ, Barber HD. Oral and maxillofacial trauma. $2^{\text {nd }}$ ed. Philadelphia: WB Saunders Co; 1997. p. 571-652.

9. Manson PN, Clark N, Robertson B. Comprehensive management of pan-facial fractures. J Craniomaxillofac Trauma 1995; 1: 43-56.

10. Terheyden H, Harle F. Surgical management of maxillary fractures. In: Booth PW, Schendel SA, Hausamen JE, editors. Maxillofacial surgery. $2^{\text {nd }}$ ed. Chapter 6. St. Louis, Missouri: Churchill Livingstone; 2007. p. 114-5.

11. Prein J. Manual of internal fixation of cranio facial skeleton. Berlin: Springer-Verlag; 1998. p. 12.

12. Manson PN, Hoopes JE, Su CT. Structural pillars of the facial skeleton: An approach to the management of Le Fort fractures. Plast Reconstr Surg 1980; 66:54-7.

13. Whitaker LA, Yaremchuk MJ. Secondary reconstruction of posttraumatic orbital deformities. Ann Plast Surg 1990; 25:440. 